\title{
Reduction of myocardial infarction by calpain inhibitors A-705239 and A-705253 in isolated perfused rabbit hearts
}

\author{
Christiane Neuhof ${ }^{1, *}$, Verena Fabiunke', Karin \\ Deibele', Maria Speth ${ }^{2}$, Achim Möller ${ }^{3}$, Wilfried \\ Lubisch $^{3}$, Hans Fritz ${ }^{4}$, Harald Tillmanns ${ }^{1}$ and \\ Heinz Neuhof ${ }^{1}$
}

${ }^{1}$ Division of Cardiology, Department of Internal Medicine, Justus-Liebig-University of Giessen, D-35392 Giessen, Germany

${ }^{2}$ Institute of Clinical Chemistry and Pathobiochemistry, Justus-Liebig-University of Giessen, D-35392 Giessen, Germany

${ }^{3}$ Neuroscience Discovery Research, Abbott GmbH \&

Co. KG, D-67008 Ludwigshafen, Germany

${ }^{4}$ Division of Clinical Chemistry and Clinical

Biochemistry, Department of Surgery, Ludwig-

Maximilians-University of Munich, D-8000 Munich, Germany

${ }^{\star}$ Corresponding author

e-mail: heinz.neuhof@innere.med.uni-giessen.de

\begin{abstract}
Introduction
Besides their physiological functions in cytoskeletal remodeling and signal transduction, calpains (calciumdependent cytosolic cysteine proteases) are also implicated in pathophysiological processes, especially with disturbed calcium homeostasis (Goll et al., 2003). Thus, calpains were found to be involved in myocardial tissue damage resulting from ischemia and reperfusion, such as sarcomer disorder, desmin degradation and proteolysis of calspectin (Yoshida et al., 1995; Papp et al., 2000). Calpain activity increases during myocardial hypoxia (lizuka et al., 1991), and activated calpains were localized by specific antibodies in infarcted regions of the human heart (Kunimatsu et al., 1999). Calpain inhibition, on the other hand, attenuates or prevents myocardial tissue damage and mitochondrial dysfunction by ischemia and reperfusion (Neuhof et al., 2003). Increased calpain activity during hypoxia (lizuka et al., 1991) can be reduced with peptidyl aldehyde calpain inhibitor-I. Calpain inhibitors were also found to be protective in prolonged hypothermic cardiac preservation (Saito et al., 1999) and against virus-induced apoptotic myocardial injury (DeBiasi et al., 2001). So far, only a few studies are available regarding the effect of calpain inhibition in experimental models of myocardial infarction, in which the infarct size could be reduced by pretreatment with the calcium-activated neutral protease inhibitor E-64c in dogs (Toda et al., 1989) or with calpain inhibitor-I in isolated perfused rat hearts (Iwamoto et al., 1999; Perrin et al., 2003). Therefore, in the present study we have evaluated the cardioprotective properties of two newly developed calpain inhibitors (Lubisch et al., 2003) in isolated perfused rabbit hearts following temporary coronary occlusion.
\end{abstract}

\section{Results}

\section{Exclusion of experiments from statistical analysis}

Four of 16 control experiments without inhibitor had to be ended before completion because of severe arrhythmias and ventricular fibrillation, and two further hearts could not be evaluated due to imperfect staining. Of the A-705253-treated hearts, 2 out of 10 experiments each with $10^{-8}, 10^{-9}$ and $10^{-10} \mathrm{M}$ inhibitor concentrations had to be excluded because of arrhythmias and ventricular fibrillation. Two poorly stained hearts were further excluded from the $10^{-10} \mathrm{M}$ treatment group. In the A-705239 experiments 2 out of 8 hearts developed arrhythmias and ventricular fibrillation and had to be ended before completion and excluded from final statistical analysis. The high exclusion rate due to severe arrhythmias and ventricular fibrillation (20-25\%), as usually observed in animal models of myocardial infarction (Ravn et al., 1999; Waagstein
Keywords: coronary perfusion; coronary occlusion; enzyme release; infarct size; left ventricular pressure. 


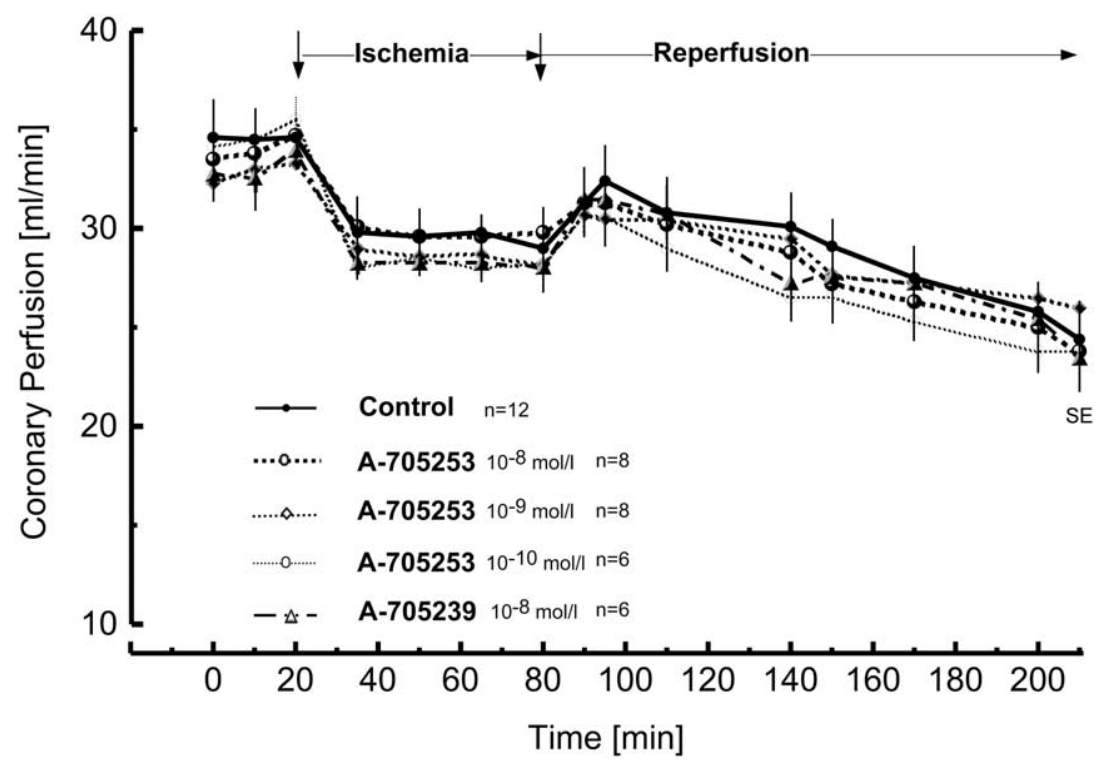

Figure 1 Time course of coronary perfusion of isolated perfused rabbit hearts.

The isolated hearts were subjected to transient occlusion of the ramus interventricularis of the left coronary artery for 60 min, followed by $120 \mathrm{~min}$ of reperfusion. Control experiments without inhibitor are represented by a solid line and inhibitor-treated hearts by dotted lines. Data are expressed as mean values \pm SEM.

et al., 1999) however, did not differ statistically between the experimental groups, and thus did not adulterate the results.

\section{Coronary perfusion, systolic left ventricular pressure and heart rate}

Coronary occlusion was immediately followed by a significant $(p<0.001)$ reduction in coronary perfusion of approximately $15.4 \%$, from its baseline of $34.5 \pm 0.6$ to $29.2 \pm 0.6 \mathrm{ml} / \mathrm{min}$ in all perfused hearts $(n=40)$. With reperfusion, coronary flow increased initially by approximately $9.1 \%$, from $28.6 \pm 0.6$ to $31.2 \pm 0.7 \mathrm{ml} / \mathrm{min}$. After $10 \mathrm{~min}$ of reperfusion the flow rate continuously decreased again to a range between 22.3 and $25.5 \mathrm{ml} /$ min. Untreated and treated hearts showed the same behavior (Figure 1).

Similarly, the systolic left ventricular pressure dropped significantly $(p<0.01)$ in all perfused hearts $(n=40)$ immediately after coronary occlusion by approximately $26 \%$, from its baseline of $77.0 \pm 1.9$ to $56.4 \pm 1.9 \mathrm{mmHg}$; however, it did not recover during reperfusion (Figure 2). There was no statistical difference between the experimental groups.

The heart rate was in the range between 190 and $165 \mathrm{~min}^{-1}$ during all experiments, except for hearts treated with $10^{-10} \mathrm{M}$ A-705253 and $10^{-8} \mathrm{M}$ A-705239, for which the heart rate decreased by approximately 20 beats $\min ^{-1}$ up to the end of reperfusion.

\section{Enzyme release from heart muscle and potassium concentration}

The concentrations of lactate dehydrogenase and creatine kinase in the perfusate increased significantly $(p<0.001)$ during reperfusion in all experiments to between 23.2 and $39.0 \mathrm{U} / \mathrm{I}$ and between 66.0 and 87.8 $\mathrm{U} / \mathrm{l}$, respectively. However, no statistical difference was found between the different experimental groups. Potas- sium levels in the perfusion fluid remained constant at between $4.611 \pm 0.010$ and $4.669 \pm 0.008 \mathrm{~mm}$ during all experiments.

\section{Area at risk and infarct size}

The area of myocardium, the so-called area at risk, which was temporarily excluded from perfusion, was $40.6 \pm 1.9 \%$ of the total left ventricle wall below the level of coronary occlusion in all hearts evaluated $(n=40)$. An infarct size (dead tissue/necrosis) of $77.9 \pm 2.3 \%$ of the area at risk was observed in untreated control hearts after 120 min of reperfusion (Figure 3). In the presence of calpain inhibitor A-705253 at a concentration of $10^{-8} \mathrm{M}$, the infarcted area was significantly $(p<0.001)$ reduced to $49.3 \pm 3.9 \%$ of the area at risk, corresponding to an infarct reduction of $61.8 \%$. This protective effect decreased with decreasing inhibitor concentrations: to $58.1 \pm 2.2 \%$ with $10^{-9} \mathrm{M}$ and to $62.1 \pm 7.3 \%$ of area at risk with $10^{-10} \mathrm{M}$. Calpain inhibitor A-705239 at $10^{-8} \mathrm{M}$ had the weakest cardioprotective effect, with a reduction of the infarcted area to only $65.8 \%$ of the area at risk.

\section{Discussion}

This study demonstrates for the first time the cardioprotective effect of two newly developed calpain inhibitors (A-705239 and A-705253) in a model of myocardial infarction in isolated perfused rabbit hearts. Both inhibitors significantly reduced the infarct size when administered prior to coronary occlusion and reperfusion.

The remarkably low inhibitor concentration of $10^{-8} \mathrm{M}$ used in these experiments, which was found to be the most effective in a recent study on global myocardial ischemia (Neuhof et al., 2003), is due to its excellent water solubility and good tissue availability (Lubisch et al., 2003) which results in a 16-fold inhibitor accumulation in the heart muscle. 


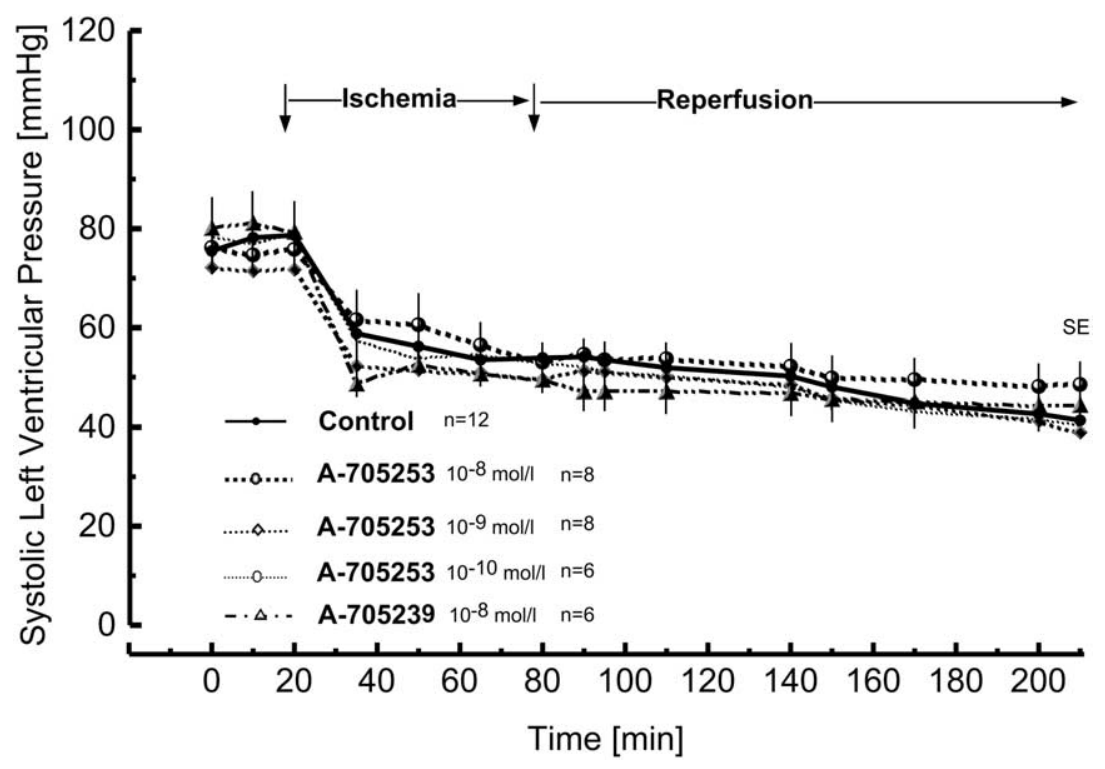

Figure 2 Time course of systolic left-ventricular pressure of isolated perfused rabbit hearts.

Hearts were subjected to transient occlusion of the ramus interventricularis of the left coronary artery for 60 min, which was followed by $120 \mathrm{~min}$ of reperfusion. Control experiments without inhibitor are represented by a solid line and inhibitor-treated hearts by dotted lines. Data are expressed as mean values \pm SEM.

Increased attention has been focused over the past two decades on calpains, besides cardiomyocyte contracture, reactive oxygen species and lysosomal proteases, as leading players in lethal myocardial cell injury during ischemia and reperfusion. Cytosolic $\mathrm{Ca}^{2+}$ overload during ischemia and reperfusion (Kihara et al., 1989; Marban et al., 1990) is considered to be mainly responsible for the activation of calcium-dependent calpains, localized primarily in the Z-disk/l-band region (Yoshimura et al., 1986; Kumamoto et al., 1992), and the subsequent breakdown of myocardial proteins. Thus, the calpaindependent degradation of desmin, calspectrin (Yoshida et al., 1995; Papp et al., 2000), troponin I and T, and

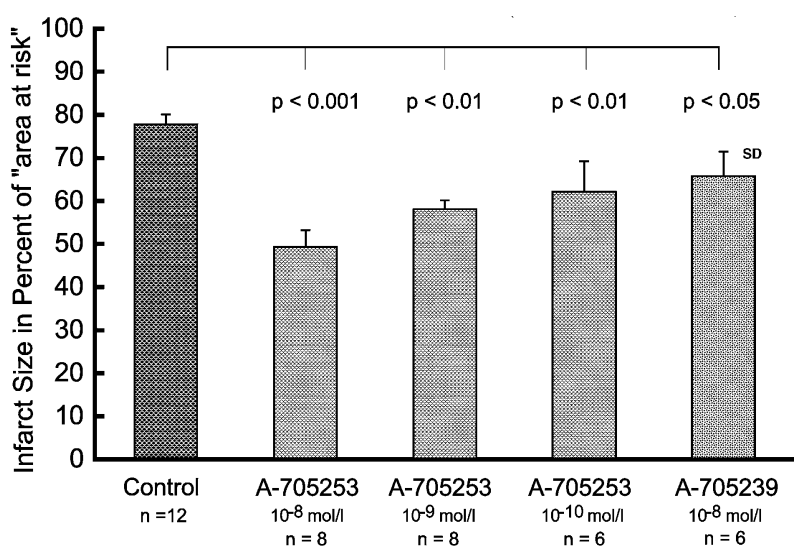

Figure 3 Development of myocardial infarction in isolated perfused rabbit hearts.

Experimental occlusion of the ramus interventricularis of the left coronary artery for $60 \mathrm{~min}$ was followed by $120 \mathrm{~min}$ of reperfusion. Infarct size is expressed in percentage of the area at risk (the transiently non-perfused myocardium). Control experiments without inhibitor are represented by a dark-colored column and inhibitor-treated hearts by light-colored columns. Data are presented as mean values $\pm S D$. Infarct size is significantly reduced by calpain inhibition in all treated hearts compared to untreated controls. sarcoplasmic reticulum proteins (Singh et al., 2004), corresponding to the myofilament disintegration observed by electron microscopy (Gao et al., 1997; Goette et al., 2002), has been reported in ischemia-reperfusion models. Furthermore, calpain activation in ischemia and reperfusion is accompanied by the downregulation of calpastatin, its natural inhibitor (Sorimachi et al., 1997; Enns et al., 2002). Besides direct myofilament disintegration, mitochondrial dysfunction is also considered to contribute essentially to cardiac dysfunction and myocyte injury during ischemia and reperfusion (Lesnefsky et al., 2001). This assumption is supported by observations that calpain inhibition (Neuhof et al., 2003) or the prevention of calpain activation by $\mathrm{Na}^{+} / \mathrm{H}^{+}$exchange inhibition (Chen et al., 2002) reduces mitochondrial dysfunction during myocardial ischemia and reperfusion.

Our results showing a decrease in infarct size by calpain inhibition in rabbits are in accordance with experimental findings in rats (Iwamoto et al., 1999; Perrin et al., 2003) and dogs (Toda et al., 1989). No reduction in the release of lactate dehydrogenase and creatine kinase by calpain inhibition, as observed after global myocardial ischemia (Chen et al., 2002; Neuhof et al., 2003; Liu and Schellmann, 2003), was found in our study with transient local ischemia. This may be due to an enzyme loss from small affected tissue volumes with insufficient concentration for detection. Differences in coronary flow between treated and untreated hearts are not expected, because infarcted areas are reperfused as well. The slowly decreasing coronary flow up to the end of the experiment can be related to increasing vascular resistance (by endothelial swelling), as also observed in normal perfused hearts without ischemia. Inhibitor-treated hearts with significantly reduced infarct size did not show better myocardial function (ventricular pressure performance) than untreated controls during $120 \mathrm{~min}$ of reperfusion. This behavior is clarified by observations that the salvage of myocardium from necrosis after local ischemia by 
reperfusion has little instant effect on systolic myocardial performance, as its functional recovery takes up to 4 weeks (Theroux et al., 1976; Lavallee et al., 1983; Ellis et al., 1985). To evaluate not only the salvage from necrosis, but also the return of function, longer experiments have to be performed in intact animals. In contrast to the infarct model, in which the time of transient local ischemia is chosen to be long enough to develop necrosis, in models of global ischemia the duration of perfusion cessation is restricted to enable at least a speedy recovery with reperfusion.

As the calpain inhibitors used in our study also inhibit the lysosomal cysteine proteases cathepsin $B$ and $L$, it should be discussed whether inhibition of both proteases could account for the cardioprotective effect. So far, poor information is available for both cathepsins in the heart. Thus, activation of cathepsin $L$ was found in the intralysosomal compartment of cardiomyocytes during coronary aortal bypass (Turski and Zaslonka, 2000). The increase in functional recovery and the decrease in protein degradation, total activity of cathepsin $B$ and $L$, and in cathepsin B leakage by cysteine proteinase inhibitors in experimental models of myocardial ischemia and infarction (Tsuchida et al., 1986; Shibata et al., 1992), however, cannot be related to both proteinases, as these inhibitors could also inhibit calpains. Recently we showed (unpublished data) that both calpain inhibitor A705253 and the $\mathrm{Na}^{+} / \mathrm{H}^{+}$exchange inhibitor Cariporide ${ }^{\circledR}$ reduced infarct size by the same degree, without an additive effect when they were combined. These findings suggest that cardioprotection in our study is due to calpain inhibition, because cathepsin $B$ and $L$ are not calcium-activated proteases and their activity would not be inhibited by an $\mathrm{Na}^{+} / \mathrm{H}^{+}$exchange inhibitor.

The novel calpain inhibitors A-705239 and A-705253 showed excellent protection against myocardial infarction after transient local coronary occlusion and reperfusion when administered prior to the onset of ischemia. These findings may suggest prophylactic calpain inhibition in clinical situations of coronary surgery and coronary angioplasty, which are often threatened by acute myocardial infarction. Its protective efficacy when administered in later stages of coronary occlusion has yet to be evaluated in further studies.

\section{Materials and methods}

This study was approved by the Institutional Animal Care and Use Committee of the Justus-Liebig-University of Giessen and was performed in accordance with the guidelines of the National Institute of Health (USA).

\section{Reagents and materials}

Calpain inhibitor A-705239 and A-705253 (Abbott GmbH \& Co $\mathrm{KG}$, Ludwigshafen, Germany) are representatives of a novel class of non-peptide calpain inhibitors, as described by Lubisch et al. (2003). They are benzoylalanine-derived ketoamides carrying vinylbenzyl amino residues in the $\mathrm{P}^{2} / \mathrm{P}^{3}$ region and inhibit calpain in nanomolar concentrations. A-705239 inhibits calpainI with a $K_{\mathrm{i}}$ of $13.3 \pm 1.5 \mathrm{nM}$, and $\mathrm{A}-705253$ with a $K_{\mathrm{i}}$ of $27 \pm 2.5 \mathrm{~nm}$ for the enzyme-inhibitor complex. Cathepsin $B$ and $L$ are inhibited by A-705239 with a $K_{\mathrm{i}}$ of $27 \pm 6$ and $22 \pm 3 \mathrm{nM}$, respectively, and are inhibited by $A-705253$ with a $K_{\mathrm{i}}$ of $62 \pm 9$ and $149 \pm 15 \mathrm{nM}$, respectively. No inhibition is detected for yeast proteasome, papain and human ICE/caspase1 at concentrations above $10 \mu \mathrm{M}$.

Poly(O-2-hydroxyethyl)-starch (HAES-steril $\left.{ }^{\circledR} \quad 10 \%\right)$ was obtained from Fresenius (Bad Homburg, Germany), and Custadiol ${ }^{\circledR}$ from Dr. F. Köhler Chemie GmbH (Alsbach-Hänlein, Germany). Na-pyruvate and 2,3,5-triphenyltetrazolium chloride were purchased from Sigma-Aldrich (Deisenhofen, Germany), and Evans blue from Merck KGaA (Darmstadt, Germany).

\section{Isolated heart preparation}

Half-breed rabbits of either sex weighing between 2.5 and $3.2 \mathrm{~kg}$ were anesthetized with pentobarbital sodium $(60-80 \mathrm{mg} / \mathrm{kg})$ and anticoagulated with heparin sodium $(1000 \mathrm{IU} / \mathrm{kg})$ injected into an ear vein. A tracheotomy was performed, and the rabbits were mechanically ventilated with room air by means of a Starling pump (B. Braun, Melsungen, Germany). The thorax was opened via the diaphragma, followed by a median sternotomy. The aorta was cannulated retrogradely and cardioplegia was induced by injection of $25-30 \mathrm{ml}$ of ice-cold $\left(4^{\circ} \mathrm{C}\right)$ Bretschneider solution $\left(\right.$ Custadiol $\left.^{\circledR}\right)$. The hearts were excised, mounted onto a modified Langendorff perfusion system and excess tissue was removed. A latex balloon (1.3-ml capacity) for pressure monitoring was inserted into the left ventricle and connected to a second extracorporeal circuit according to the 'working' heart model, as described by Bardenheuer and Schrader (1983). Left end-diastolic influx pressure (preload) was set hydrostatically to $7 \mathrm{mmHg}$ and 'aortic' pressure (afterload) to $50 \mathrm{mmHg}$ by means of a water-filled reservoir and the height of the outflow tube, respectively. After a cardioplegic arrest of 3-4 min, the hearts were perfused retrogradely with a constant hydrostatic pressure of $70 \mathrm{mmHg}$ with oxygenated Krebs-Henseleit-HAES buffer at $37^{\circ} \mathrm{C}$, which was filtered through a $0.2-\mu \mathrm{m}$ Pall filter (Pall Biomedical Inc, Fajardo, Puerto Rico). The buffer was bubbled with a mixture of $95 \% \quad \mathrm{O}_{2}$ and $5 \% \quad \mathrm{CO}_{2}$ resulting in $\mathrm{PO}_{2}$ of $>400 \mathrm{mmHg}$ in the perfusate and $>200 \mathrm{mmHg}$ in the coronary effluent, and the $\mathrm{pH}$ was maintained between 7.35 and 7.45 by increasing or decreasing the $\mathrm{CO}_{2}$ admixture. During experiments, the spontaneously beating hearts were submerged in a container (25-ml capacity) at $37^{\circ} \mathrm{C}$ filled with the coronary effluent to prevent exsiccation. Coronary perfusion pressure and coronary flow were measured continuously with a pressure transducer (Combitrans ${ }^{\circledR}$, B. Braun) and electromagnetic flow probe (Empo/Gould, Oxnard, USA), respectively, in the perfusion line. Left ventricular pressure (LVSP) and end-diastolic pressure (LVEP) were measured with another pressure transducer connected to a balloon inserted into the cavity of the left ventricle. Isovolumetric left ventricular pressure was measured intermittently by clamping off the connections to the inflow reservoir and the outflow tube. A bipolar electrocardiogram was conducted from apex versus heart base. All these parameters were monitored continuously and recorded on a multichannel recorder.

\section{Perfusate}

For perfusion, a modified Krebs-Henseleit buffer solution (KHHB) with Na-pyruvate $(0.5 \mathrm{~g} / \mathrm{l})$ was prepared, and hydroxyethyl starch (HAES-steril $^{\circledR} 10 \%$ ) was added to keep colloid oncotic pressure between 23 and $25 \mathrm{mmHg}$, yielding the following final concentrations: starch, $50 \mathrm{~g} / \mathrm{l} ; \mathrm{Na}^{+}, 138 \mathrm{mM} ; \mathrm{K}^{+}, 4.5 \mathrm{mM} ; \mathrm{Mg}^{2+}$, $1.33 \mathrm{~mm} ; \mathrm{Cl}^{-}, 135 \mathrm{~mm}$; $\mathrm{Ca}^{2+}, 2.38 \mathrm{~mm}$; glucose, $12 \mathrm{~mm}$; Napyruvate, $4.5 \mathrm{~mm}$; and $\mathrm{HCO}_{3}^{-}, 12 \mathrm{~mm}$. Osmolality was approximately $330 \mathrm{mosmol} / \mathrm{kg}$. The $\mathrm{pH}$ of the perfusate was adjusted to 7.4 with $1 \mathrm{M} \mathrm{NaHCO}_{3}$ before use. Oncotic pressure and osmolality were controlled with an Onkometer (BMT 921, Dr. Karl Tho- 
mae, Biberach, Germany) and a Mikro-Osmometer (Roebling Messtechnik, Berlin, Germany).

\section{Experimental protocol}

Perfused hearts were stabilized for $20 \mathrm{~min}$. After this steadystate period, the ramus interventricularis of the left coronary artery was blocked by means of a tourniquet just below the origin of the first diagonal branch for $60 \mathrm{~min}$. Hearts selected for the study were those that developed a constant systolic left ventricular pressure of more than $60 \mathrm{mmHg}$ during the steady-state period. After $60 \mathrm{~min}$ of occlusion the tourniquet was reopened and the coronary reperfused for $120 \mathrm{~min}$.

In 10 perfused hearts each, calpain inhibitor A-705253 was added to the perfusate from the beginning of perfusion at final concentrations of $10^{-8}, 10^{-9}$, and $10^{-10} \mathrm{M}$, respectively. In a further 6 experiments inhibitor A-705239 was used at a final concentration of $10^{-8} \mathrm{M}$. Sixteen hearts were treated without inhibitor as controls.

\section{Measurements}

Isovolumetric left ventricular pressure amplitude and heart rate were determined from pressure records and electrocardiograms, respectively. Coronary flow was monitored continuously with an electromagnetic flow transducer. Samples of coronary effluent were collected intermittently for control of $\mathrm{pH}, \mathrm{PO}_{2}$, and $\mathrm{PCO}_{2}$, and for determination of creatine kinase and lactate dehydrogenase activity using kits from Boehringer-Mannheim (Mannheim, Germany).

\section{Determination of area at risk and infarct size}

At the end of each experiment perfusion was stopped and the ramus interventricularis of the left coronary artery was closed again using the tourniquet. Five $\mathrm{ml}$ of Evans blue (5\%) was injected via the perfusion catheter into the coronary circulation to stain the non-ischemic zone blue and to demarcate the area at risk. The atria, right ventricle, and great vessels were removed and the left ventricle was cut in 7-8 slices of approximately $3 \mathrm{~mm}$ in thickness, which were then incubated in 2,3,5-triphenyltetrazolium chloride (1\%) for $15 \mathrm{~min}$ at a temperature of $37^{\circ} \mathrm{C}$. By this procedure, normal perfused myocardium was stained blue and the viable tissue within the area at risk was stained red, whereas the infarcted dead myocardium remained unstained. The stained slices were photographed on both sides by means of a digital camera (Coolpix 950, Nikon Corp, Tokyo, Japan). The computer programs Paint Shop Pro6 (Jasc Software Inc, Eden Prairie, MN, USA) and Image $\mathrm{J}(\mathrm{NIH}, \mathrm{USA})$ were used for color discrimination and planimetric evaluation of normal perfused myocardium, the area at risk, and infarct size. Both sides of each left ventricle slice were evaluated and the areas corresponding to different colors were added up. Infarct size (dead myocardium) was expressed as percentage of area at risk (the temporarily non-perfused myocardium due to the $60 \mathrm{~min}$ of coronary occlusion).

\section{Statistics}

The data were analyzed by means of the Statgraphics-Plus ${ }^{\circledR}$ statistical analysis package from Statistical Graphics Corporation (Rockville, MD, USA). Intergroup analysis was performed by analysis of variance. Fisher's LSD test was used for multiple group comparison. Data are presented as mean \pm standard error of the mean. A significant difference was defined as $p<0.05$.

\section{Acknowledgments}

The authors thank Mrs. Tiziana Wieth for editing the manuscript and Mrs. Antje Weber and Mr. Harald Michnacs for excellent technical assistance.

\section{References}

Bardenheuer, H., and Schrader, J. (1983). Relationship between myocardial oxygen consumption, coronary flow, and adenosine release in an improved isolated working heart preparation of guinea pigs. Circ. Res. 52, 263-271.

Chen, M., Won, D.J., Krajewski, S., and Gottlieb, R.A. (2002). Calpain and mitochondria in ischemia/reperfusion. J. Biol. Chem. 277, 29181-29186.

DeBiasi, R.L., Edelstein, C.L., Sherry, B., and Tyler, K.L. (2001). Calpain inhibition protects against virus-induced apoptotic myocardial injury. J. Virol. 75, 351-361.

Ellis, S.G., Henschke, C.I., Sandor, T., Wynne, J., and Kloner, R.A. (1985). Relation between the transmural extent of acute myocardial infarction and associated myocardial contractility two weeks after infarction. Am. J. Cardiol. 55, 1412-1416.

Enns, D., Karmazyn, M., Mair, J., Lercher, A., Kountchev, J., and Belcastro, A. (2002). Calpain, calpastatin activities and ratios during myocardial ischemia-reperfusion. Mol. Cell. Biochem. 241, 29-35.

Gao, W.D., Atar, D., Liu, Y., Perez, N.G., Murphy, A.M., and Marban, E. (1997). Role of troponin I proteolysis in the pathogenesis of stunned myocardium. Circ. Res. 80, 393-399.

Goette, A., Arndt, M., Röcken, C., Staack, T., Bechtloff, R., Reinhold, D., Huth, C., Ansorge, S., Klein, H.U., and Lendeckel, U. (2002). Calpains and cytokines in fibrillating human atria. A.J.P. Heart Circ. Physiol. 283, H264-H272.

Goll, D.E., Thompson, V.F., Li, H., Wei, W., and Cong, J. (2003). The calpain system. Physiol. Rev. 83, 731-801.

lizuka, K., Kawaguchi, H., and Yasuda, H. (1991). Calpain is activated during hypoxic myocardial cell injury. Biochem. Med. Metab. Biol. 46, 427-431.

Iwamoto, H., Miura, T., Okamura, T., Shirakawa, K., Iwatate, M., Kawamura, S., Tatsuno, H., Ikeda, Y., and Matsuaki, M. (1999). Calpain inhibitor-I reduces infarct size and DNA fragmentation of myocardium in ischemic/reperfused rat heart. J. Cardiovasc. Pharmacol. 33, 580-586.

Kihara, Y., Grossman, W., and Morgan, J.P. (1989). Direct measurement of changes in intracellular calcium transient during hypoxia, ischemia, and reperfusion of the intact mammalian heart. Circ. Res. 65, 1029-1044.

Kumamoto, T., Kleese, W.C., Cong, J.Y., Goll, D.E., Pierce, P.R., and Allen, R.E. (1992). Localization of the $\mathrm{Ca}^{2+}$-dependent proteinases and their inhibitor in normal, fasted, and denervated rat skeletal muscle. Anat. Res. 232, 60-77.

Kunimatsu, M., Tada, T., Narita, Y., Ozaki, Y., Liu, Z.-Q., Shearer, T.R., and Sasaki, M. (1999). Activation of calpain in myocardial infarction: an immunohistochemical study using a calpain antibody raised against active site histidine-containing peptide. Cardiovasc. Pathol. 8, 7-15.

Lavallee, M., Cox, D., Patrick, T.A., and Vatner, S.F. (1983). Salvage of myocardial function by coronary artery reperfusion 1,2 , and 3 hours after occlusion in conscious dogs. Circ. Res. 53, 235-247.

Lesnefsky, E.J., Moghaddas, S., Tandler, B., Kerner, J., and Hoppel, C.L. (2001). Mitochondrial dysfunction in cardiac disease: ischemia-reperfusion, aging, and heart failure. J. Mol. Cell Cardiol. 33, 1065-1089.

Liu, X., and Schellmann, R.G. (2003). Calpain mediates progressive plasma membrane permeability and proteolysis of cytoskeleton-associated paxillin, talin, and vinculin during renal cell death. J. Pharmacol. Exp. Ther. 301, 63-70. 
Lubisch, W., Beckenbach, E., Bopp, S., Hofmann, HP., Kartal, A., Kästel, C., Lindner, T., Metz-Garrecht, M., Reeb, J., Regner, F., et al. (2003). Benzoylalanine-derived ketoamides carrying vinylbenzyl amino residues: discovery of potent calpain inhibitors with oral bioavailability. J. Med. Chem. 46, 2404-2412.

Marban, E., Kitakaze, M., Koretsune, Y., Yue, D.T., Chacko, V.P., and Pike, M.M. (1990). Quantification of $\left[\mathrm{Ca}^{2+}\right]_{i}$ in perfused hearts. Critical evaluation of the 5F-BAPTA and nuclear magnetic resonance method as applied to the study of ischemia and reperfusion. Circ. Res. 66, 1255-1267.

Neuhof, C., Götte, O., Trumbeckaite, S., Attenberger, M., Kuzkaya, N., Gellerich, F., Möller, A., Lubisch, W., Speht, M., Tillmanns, H., and Neuhof, H. (2003). A novel water-soluble and cell-permeable calpain inhibitor protects myocardial and mitochondrial function in postischemic reperfusion. Biol. Chem. 384, 1597-1603.

Papp, Z., van der Velden, J., and Stienen, G.J. (2000). CalpainI induced alterations in the cytoskeletal structure and impaired mechanical properties of single myocytes of rat heart. Cardiovasc. Res. 45, 981-983.

Perrin, B.J., and Huttenlocher, A. (2002). Molecules in focus calpain. Int. J. Biochem. Cell Biol. 34, 722-725.

Perrin, C., Ecarnot-Laubriet, A., Vergely, C., and Rochette, L. (2003). Calpain and caspase-3 inhibitors reduce infarct size and post-ischemic apoptosis in rat heart without modifying contractile recovery. Cell. Mol. Biol. 49, 497-505

Ravn, H.B., Moeldrup, U., Brookes, C.I.O., Ilkjaer, L.B., White, P., Chew, M., Jensen, L., Johnson, S., Birk-Soerensen, L., and Hjortdal, V.E. (1999). Intravenous magnesium reduces infarct size after ischemia/reperfusion injury combined with a thrombogenic lesion in the left anterior descending artery. Arterioscler. Thromb. Vasc. Biol. 19, 569-574.

Saito, T., Mishima, A., Asano, M., Ukai, T., Yamamoto, S., Kunimatsu, M., Sasaki, M., and Manabe, T. (1999). Protective effects of calpain inhibitor for prolonged hypothermic cardiac preservation. Jpn. J. Thorac. Cardiovasc. Surg. 47, 145-152.

Shibata, T., Yamamoto, F., Ohashi, T., Nakajima, N., Kinoshita, H., and Kawashima, Y. (1992). The effect of protease inhibitor upon the ischemia-reperfusion injury. Nippon Kyobu Grka Gakkai Zasshi 40, 1853-1858.
Singh, R.B., Chohan, P.K., Dhalla, N.S., and Netticadan, T. (2004). The sarcoplasmic reticulum proteins are targets for calpain action in the ischemic-reperfused heart. J. Mol. Cell. Cardiol. 37, 101-110.

Sorimachi, Y., Harada, K., Saido, T.C., Ono, T., Kawahima, S., and Yoshida, K. (1997). Downregulation of calpastatin in rat heart after brief ischemia and reperfusion. J. Biochem. (Tokyo) 122, 743-748.

Theroux, P., Ross Jr., J., Franklin, D., Kemper, W.S., and Sasayama, S. (1976). Coronary arterial reperfusion. III. Early and late effects on regional myocardial function and dimensions in conscious dogs. Am. J. Cardiol. 38, 599-606.

Toda, G., Matsushita, S., Kuramoto, K., Oda, S., Ezaki, H., Hattori, A., and Kawashima, S. (1989). Calcium-activated neutral protease inhibitor (E-64c) and reperfusion for experimental myocardial infarction. Jpn. Heart J. 30, 375-386.

Tsuchida, K., Aihara, H., Isogai, K., Hanada, K., and Shibata, N. (1986). Degradation of myocardial structural proteins in myocardial infarcted dogs is reduced by Ep459, a cysteine proteinase inhibitor. Biol. Chem. Hoppe-Seyler 367, 39-45.

Turski, W.A., and Zaslonka, J. (2000). Activity of cathepsin D and $L$ in the heart muscle of coronary patients during coronaryaortal bypass graft operation. Med. Sci. Monit. 6, 853-860.

Waagstein, L.M., Wennberg, E., Waagstein, F., and Haljamäe, H. (1999). Hypertonic saline without or with dextran-70 in the treatment of experimental acute myocardial ischemia and reperfusion. Crit. Care Med. 27, 605-616.

Yoshida, K., Inui, M., Harada, K., Saido. T.C., Sorimachi, Y., Ishihara, T., Kawashima, S., and Sobue, K. (1995). Reperfusion of rat heart after brief ischemia induces proteolysis of calspectin (nonerythroid spectrin or fodrin) by calpain. Circ. Res. 77, 603-610.

Yoshimura, N., Murachi, T., Heath, R., Kay, J., Jasand, B., and Newman, G.R. (1986). Immunogold electron-microscopic localization of calpain I in skeletal muscle of rats. Cell Tissue Res. 244, 265-270.

Received August 22, 2004; accepted September 22, 2004 